\title{
Preparation of red cell concentrates in low-income countries: Efficacy of whole blood settling method by simple gravity in Burkina Faso
}

\author{
Salam Sawadogo, Kompingnin Nébié, Eléonore Kafando, \\ Tieba Millogo, Siaka Ouattara, Honorine Dahourou, Georges Ouédraogo, \\ Sibiri Nana, Véronique Deneys
}

\begin{abstract}
Aim: This study aims to describe the characteristics of the red cell concentrates (RCCs) produced by whole blood settling in Burkina Faso. Methods: We conducted a cross-sectional study in the blood centers of Ouagadougou and Koudougou between 12th February and 15th March 2015. 427 blood units selected at Koudougou and divided into three groups were processed by settling method over three durations (methods I $=36-48 \mathrm{~h}, \mathrm{II}=48-72$ $h$ and III $=72-96 \mathrm{~h})$. Other 139 units selected at Ouagadougou were processed by centrifugation (method IV). The RCCs units' characteristics were described by the mean of their hematocrit, volume, hemoglobin level and content. The residual plasma level, the hematocrit yield and the hematocrit concentration ability (ability of method to raise hematocrit in comparison with whole blood) have been used to assess methods efficacy. Results: The volume and
\end{abstract}

Salam Sawadogo ${ }^{1,2}$, Kompingnin Nébié ${ }^{1,2}$, Eléonore Kafando $^{1}$, Tieba Millogo ${ }^{3}$, Siaka Ouattara ${ }^{2}$, Honorine Dahourou ${ }^{2}$, Georges Ouédraogo ${ }^{2}$, Sibiri Nana ${ }^{2}$, Véronique Deneys ${ }^{4}$

Affiliations: ${ }^{1}$ Hematology Laboratory, University Ouaga I Professeur Joseph KI-ZERBO, Ouagadougou, Burkina Faso; ${ }^{2}$ National Blood Transfusion Centre, Ouagadougou, Burkina Faso; ${ }^{3}$ African Institute of Public Health, Ouagadougou, Burkina Faso; ${ }^{4}$ Transfusion service, CHU UCL Namur, Catholic University of Louvain, Brussels, Belgium.

Corresponding Author: Salam Sawadogo, 01 BP 865 Ouagadougou 01, Burkina Faso; Email: salemserein@hotmail. com

Received: 24 April 2016

Accepted: 07 June 2016

Published: 04 July 2016 hemoglobin content of overall units met standard requirements. $2.1 \%, 14.2 \%$ and $27.7 \%$ of units respectively issued from methods I, II, III had hematocrit over $50 \%$. The average volume (mL) was 372.88, 357.91, 350.30 and 332.26 respectively for method I to IV $(p<0.05)$. The mean hematocrit (\%) was respectively 45.42, 47.41, 48.24 and 62.28 (non-significant difference between methods II and III). The hematocrit concentration ability was respectively 1.14, 1.22, 1.24 and 1.51 and the proportion of residual plasma $0.39,0.33,0.30$ and 0.09 . Conclusion: The RCCs obtained by settling method did not meet all standards. But we can hypothesize that they would be more effective and safe for patients. However, it is necessary to undertake further studies to verify it.

Keywords: Blood sedimentation, Centrifugation, Gravity

\section{How to cite this article}

Sawadogo S, Nébié K, Kafando E, Millogo T, Ouattara S, Dahourou H, Ouédraogo G, Nana S, Deneys V. Preparation of red cell concentrates in low-income countries: Efficacy of whole blood settling method by simple gravity in Burkina Faso. Int J Blood Transfus Immunohematol 2016;6:20-29.

Article ID: 100025IJBTISS2016

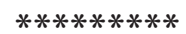

doi:10.5348/ijbti-2016-25-OA-5 


\section{INTRODUCTION}

Whole blood (WB) has currently very few indications. Indeed, the blood component therapy, the new approach in blood transfusion relied on the administration of the blood component just needed by the patient and the removal of unwanted elements $[1,2]$.

In Sub-Saharan African countries, the main indication for blood transfusion is anemia caused by malaria, malnutrition and other genetic dysfunctions of red blood cells (RBCs) such as sickle cells disease, thalassemia, etc. [3]. Indeed, the community prevalence of anemia in children, defined as a hemoglobin rate $(\mathrm{Hb})<110 \mathrm{~g} / \mathrm{L}[4]$, ranges from $49-89 \%$ and severe anemia affects between 1 and $6 \%$ of children. In hospitalized children, prevalence of severe anemia ranges from $8-33 \%$ according to different studies [4-6], resulting in a high demand for blood transfusions (accounted for 45-67\%) [5, 6].

The aim of blood transfusion in such situations is to help to restore the primary function of RBCs, namely the transport of oxygen from lungs to tissues and carbon dioxide from tissues to lungs. Thus, the most appropriate treatment is the administration of RCCs.

Commonly, RCCs and other blood components are obtained by centrifugation methods with programmable centrifuges and blood components separators (automatic or not) after whole blood collection, or through aphaeresis process [7]. These techniques require important facilities and heavy investments (specific infrastructures, expensive equipment, welltrained staff, and well-controlled procedures) [8, 9]. New separations' technologies using closed-system gravity filtration with hollow-fibers system has also been developed [9-11]. In Sub-Saharan African lowincome countries, either centrifugation/aphaeresis methods or gravity filtration system are all often out of reach. Blood transfusion services have neither the economic resources nor the technical capacities to implement these processes. Limited financial resources, shortage of trained staff and the poor electrification of these settings are the main constraints. In addition, the absence of health financing system (health insurance, social security, ...) does not allow reimbursement of production costs for sophisticated blood components such as RCCs, platelet concentrates (PCs), fresh-frozen plasma (FFP), etc. In some countries (Senegal, Mali and Ghana), patients or their families contribute partially to the costs of blood components production; while in some others such as Burkina Faso, blood products are free of charge for patients [12]. This does not allow blood transfusion services to mobilize enough resources to support the implementation and maintenance of heavy technologies and ensure service running costs. So, the main available blood product is WB with high risks of adverse reactions $[13,14]$ such as allergic reactions, transfusion-associated circulatory overload, nonhemolytic febrile reactions, transfusion-related acute lung injury, minor immunological incompatibility in case of compatible no ABO identical WB transfusion and ineffective blood transfusions.

In Burkina Faso, given the epidemiological and technical context characterized by high level of blood demands to correct severe anemia and the lack of logistics to prepare blood components (NBTC annual reports of last five years), the Regional blood transfusion centre (RBTC) of Koudougou has chosen to produce RCCs units by settling WB by simple gravity. This technique implemented since 2008 and is authorized by the national regulatory, but no requirement was issued for such products.

This study was carried out to describe the hematological and volume parameters of these RCCs units and to compare them to requirements applied to RCCs units processed with common methods.

\section{MATERIALS AND METHODS}

\section{Study setting}

The blood transfusion system in Burkina Faso is theoretically based on a centralized administrative management. The National Blood Transfusion Centre (NBTC) has four RBTCs that do not yet cover the whole country. Currently, over 40 independent hospital based blood banks are collecting, testing and distributing exclusively WB to patients [15]. Seven new RBTCs are needed to achieve a full coverage of the country. Blood collection is performed at fixed and mobile donor sites according to the National guidelines [16]. Our study was carried out in two RBTCs: the RBTC of Ouagadougou and Koudougou.

The RBTC of Ouagadougou is the biggest of the country. Annually, around 32,00o blood units are collected and around 35,000 blood components are produced in this centre. The RCCs account for more than $85 \%$ of blood products processed. FFP and PCs represent the remaining $15 \%$. The RBTC of Koudougou, located 100 $\mathrm{km}$ away from Ouagadougou produces annually around 10,000 RCCs exclusively (NBTC, Annual report 2014).

The quality control of blood products is performed with regard to national standards requirements [17].

\section{Donors, blood collection and whole blood units}

The blood units included in this cross-sectional analysis were collected between 12th February and 15th March 2015 in the two RBTCs, Koudougou $(n=427)$ and Ouagadougou $(n=139)$. They were non-reactive for the markers of major transfusion-transmitted infections (human immunodeficiency virus, hepatitis B and C viruses, and syphilis). All the WB units were collected from healthy male and female voluntary non-remunerated blood donors aged between 18-60 years and weighing $50 \mathrm{~kg}$ at least. Blood donations were performed in both 
RBTC according to harmonized procedures. Blood donors underwent pre-donation medical selection using standardized questionnaire, measuring of hemodynamic parameters (blood pressure and pulse) and finger predonation hemoglobin test with photometer analyzers. According to the pattern of hemoglobin rate distribution in the general population, only voluntary donors with a minimum hemoglobin rate of $105 \mathrm{~g} / \mathrm{L}$ and $115 \mathrm{~g} / \mathrm{L}$ respectively in women and men are qualified for blood donation ("CNTS/DCSAQ - COL_Doo1 - Document cadre de collecte”).

Blood is collected into an inter-connected series of three plastic sterile bags (main collection and two transfer bags). The main collection bag contains $63 \mathrm{~mL}$ of Citrate Phosphate Dextrose (CPD) anticoagulant and one of the transfer bags contains $100 \mathrm{~mL}$ of saline, adenine, glucose and mannitol (SAGM) preservative solution [18, 19]. A volume of $450 \pm 50 \mathrm{~mL}$ (anticoagulant taken into account) of WB is collected per bag. Immediately after the blood collection the inlet tubing of the collection bag was sterilely sealed at around $30 \mathrm{~cm}$ of the bag. Before storage in refrigerated temperature $\left(2-6^{\circ} \mathrm{C}\right)$, all the donated $\mathrm{WB}$ units are left to rest at room temperature $\left(20-25^{\circ} \mathrm{C}\right)$ for 6 hours maximally in order to favor further phagocytosis by leukocytes.

\section{RCCs processing}

The selected WB units were divided into four groups as outlined in Table 1 . The WB units of each group were matched to the units of the other groups on the basis of their net volume $\pm 10 \mathrm{~mL}$. The first three groups comprise units that were selected from the RBTC of Koudougou. They all underwent WB settling methods by simple gravity over different settling durations: $36-48 \mathrm{~h}$ for method I (group I; $\mathrm{n}=145$ ); 48-72 h for method II (group II; $\mathrm{n}=141$ ) and $72-96 \mathrm{~h}$ for method III (group III; $\mathrm{n}=$ 141). The WB bags are arranged vertically in monitored $2-6^{\circ} \mathrm{C}$ refrigerator to allow RBCs' sedimentation in the bottom of bag. No centrifugal force was applied. After the predetermined settling duration, plasma is expulsed in the attached transfer bag, using manual plasma extractors. The extracted plasma is discarded and the RBCs remaining in the main collection bag are secondarily re-suspended in a SAGM solution. The last group (group IV; reference group; $\mathrm{n}=139$ ) comprises WB units selected from the RBTC of Ouagadougou that were processed into RCCs by centrifugation method (method IV). Programmable refrigerated centrifuges are used. WB units were centrifuged at $2490 \mathrm{~g}$ for 20 minutes within 48 hours after collection. Plasma is extracted manually (manual pressing devices) in a closed system. Plasma and RCCs (secondarily re-suspended in SAGM solution) are stored for therapeutic use if they comply with standards.

\section{Assessment of hematological and volume characteristics of WB}

WB volume (WB_vol; $\mathrm{mL}$ ) was determined by converting the unit net mass in volume, using $1.06 \mathrm{~g} /$ $\mathrm{mL}$ as the value of specific gravity of WB. Hemoglobin rate (WB_Hb;g/dL) and hematocrit (WB_Hct; \%) of WB were measured with HemoControl ${ }^{\circledR}$ photometer analyzers from blood sampled during donation process in an anticoagulant tube (tube EDTA) within 24 hours after collection. The plasma volume in WB was calculated by the following formula [20]: Plasma Volume $(\mathrm{mL})=$ WB_vol (mL)x(1-WB_Hct (\%)/10o). All the units mass are weighted using electronic balances (ADAM $\left.{ }^{\circledR}\right)$.

\section{Assessment of hematological and volume characteristics of RCCs}

Volume of RCCs units (RCC_vol; mL) was calculated by dividing (before any sampling) the unit net mass (unit mass minus the tare weight of the bag) by the specific gravity of RCCs re-suspended in SAGM solution (1.07 $\mathrm{g} / \mathrm{mL}$ ). The RCCs hemoglobin level (RCC_Hb; g/dL) and hematocrit (RCC_Hct; \%) were determined with a automate BC300o-plus ${ }^{\circledR} \quad$ (MINDRAY Corporation Chenzen, China) on $2 \mathrm{~mL}$ of blood sampled by stripping method (with respect for blood units' integrity and quality) after agitation for 5 min with AGITATOR TS2000 ${ }^{\circledR}$. The RCC_Hb was multiplied by the RCC_vol in order to determine hemoglobin content per RCC unit (RCC_Hb-c; g). For all RCCs units, the $\mathrm{Hb}$ rate was measured within $24 \mathrm{~h}$ after processing.

\section{Assessment of efficacy of RCCs processing methods}

In order to assess the efficacy of RCCs processing methods, we used the proportion of residual plasma in RCCs units (residual plasma volume (mL) divided by plasma volume (mL) in WB), the hematocrit concentration yield (Hct_yield; \%) of each method (difference between the RCC_Hct (\%) and the WB_Hct (\%)) and the ability of each method to raise hematocrit in final RCCs unit in comparison with WB unit (hematocrit concentration ability; Hct_ability). The Hct_ability was given by the quotient of RCC_Hct (\%) with WB_Hct (\%) and the residual plasma (RCC_rp; $\mathrm{mL}$ ) was calculated using the following formula [21]: Residual plasma $=$ RCC_Vol $(\mathrm{mL})$ $\mathrm{x}\left(1-\mathrm{RCC} \_\right.$Hct (\%)/100) - Preservative solution volume.

\section{Statistical analyses}

The analyses were performed with STATA 13.1. We used proportion (\%), mean $\pm \mathrm{SD}$ or $\mathrm{SE}$ and ranges to describe characteristics of our sample and to assess the compliance of RCCs units with standard values defined in applicable regulatory. Comparisons were made between the RCCs obtained from the different processing methods using ANOVA test. A Tukey's HSD test (a post hoc test) was 
performed after ANOVA to provide further comparisons between the methods with the objective to identify the most effective one between the settling methods. For all analyses, significance was accepted if $\mathrm{p}<0.05$.

\section{Ethical considerations}

The study was authorized by management team and medical commission of the NBTC of Burkina Faso. All the blood donors are volunteers and non-remunerated. Collected data were those allowed by blood donation regulatory. The confidentiality of study participants was fully respected using identification numbers and removing all personal information. All blood samples taken from blood units have preserved their integrity and quality. They have subsequently been issued for patients.

\section{RESULTS}

\section{Donors and whole blood units' parameters}

The sampled WB units were mainly collected (79.7 $\%)$ from male donors. The mean age of blood donors was $23.45 \pm 5.64$ years; range $18-55$. Table 2 gives sex-ratio, age (mean $\pm \mathrm{SD}$; [range]) of blood donors, hematological and volume parameters (mean $\pm \mathrm{SD}$; [range]) of WB units selected for each group. The groups I, II and III were statistically similar with respect to all these parameters (Table 2).

\section{Characteristics of RCCs units}

The volume and hemoglobin content of all RCCs units processed either by settling methods or by centrifugation met regulatory requirements. The mean hemoglobin content of RCCs from methods I to IV RCCs were respectively $57.57 \pm 5.11 \mathrm{~g}$; range [43.62-68.28], $56.68 \pm 5.24 \mathrm{~g}$; range [47.01-68.85], 56.66 $\pm 5.17 \mathrm{~g}$; range [44.70-69.78] and 63.91 $\pm 5.26 \mathrm{~g}$; range [51.21-75.95]. As stated in Table 3, only the centrifugation method gave $100 \%$ of RCCs units with a hematocrit complying with national regulatory requirements (equal or over $50 \%$ ). Among RCCs processed according to the three settling durations (i.e., methods I to III) respectively $2.1 \%$; $14.2 \%$ and $27.7 \%$ complied with hematocrit requirements.

The characteristics of RCCs obtained from the four blood components' processing methods are shown in Figure 1 ( $\mathrm{a}=$ RCC_vol; $\mathrm{b}=\mathrm{RCC} \_H c t ; \mathrm{c}=\mathrm{RCC} \_H b$ and $\mathrm{d}=$ RCC_Hb-c). The average volume of RCCs (RCC_ vol) processed by methods I to IV were respectively $372.88 \pm 17.76 \mathrm{~mL}, 357.91 \pm 20.52 \mathrm{~mL}, 350.30 \pm 22.20 \mathrm{~mL}$ and $332.26 \pm 21.81 \mathrm{~mL}$ (ANOVA test, $\mathrm{p}<0.001$ ). The mean RCC_Hct were respectively $45.42 \pm 2.60 \%, 47.41 \pm 3.01 \%$, $48.24 \pm 2.92 \%$ and $62.28 \pm 2.95 \%$ (ANOVA test, $\mathrm{p}<0.001$ ). The comparison of the 4 methods using Tukey's HSDtest (critical HSD-test value $=3.64$ ) shown significant differences between all the methods concerning the RCCs' characteristics, with exception of hematocrit, hemoglobin level and hemoglobin content (Table 4). The method II (settling time between $48-72 \mathrm{~h}$ ) seems to be similar to method III (settling time over $72 \mathrm{~h}$ ) with respect to hematocrit (HSD-test value $=3.41)$ and hemoglobin level $($ HSD-test value $=3.63)$.

\section{Efficacy of RCCs processing methods}

The residual plasma volume and the hematocrit concentration yield were presented in Figure $1(\mathrm{e}=\mathrm{RCC}$ $\mathrm{rp}$ and $\mathrm{f}=$ Hct_yield). The residual plasma volume in the RCCs prepared by methods I to IV accounted for an average proportion of $0.39 \pm 0.03,0.33 \pm 0.04,0.30 \pm 0.04$ and $0.09 \pm 0.04$ of the total plasma volume in WB unit ( $63 \mathrm{~mL}$ of anticoagulant taken into account). The average hematocrit concentration abilities of the four methods were respectively $1.14 \pm 0.05,1.22 \pm 0.06,1.24 \pm 0.06$ and 1.51 \pm 0.11 . Differences between methods were statistically significant (ANOVA test, $\mathrm{p}<0.001$ ). With Tukey's test, the difference between the methods II and III was nonsignificant with respect to the hematocrit yield (HSD-test value $=2.98$ ) and the hematocrit concentration ability $($ HSD-test value $=2.22)($ Table 4$)$.

\section{DISCUSSION}

The WB settling method gave RCCs units with an average hematocrit of $6.74-9.58 \%$ lower than

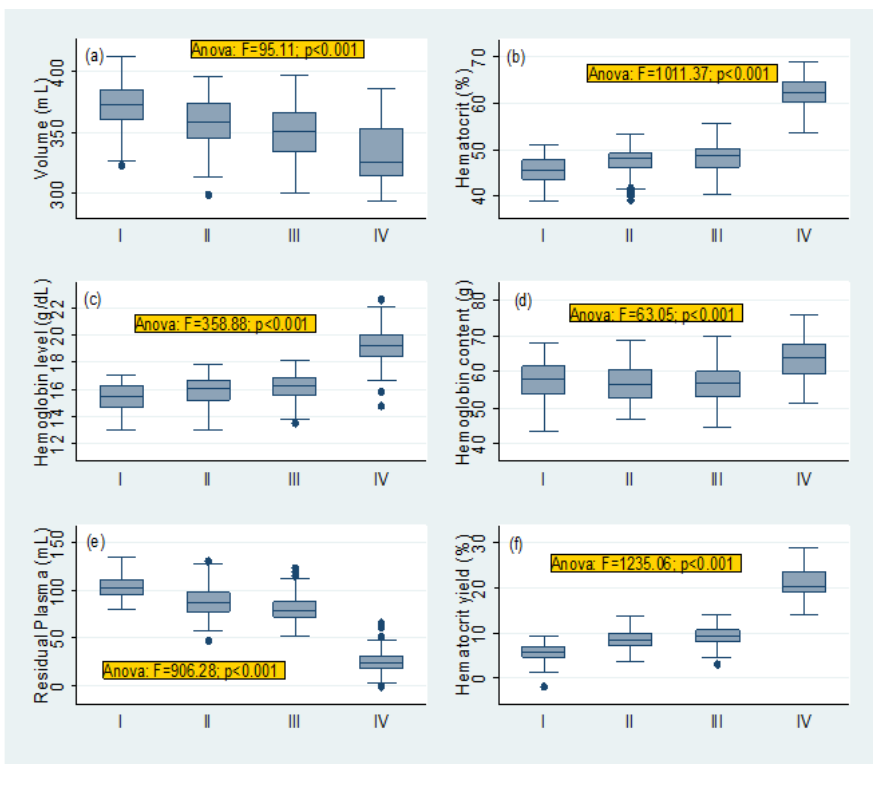

Figure 1: Blood components characteristics and efficacy parameters of processing methods. Box plots displays (a) Volume, (b) Hematocrit, (c) Hemoglobin level, (d) Hemoglobin content, (e) Residual plasma levels and (f) Hematocrit concentration yield in components produced by methods as outlined in Table I. Boxes display the $75^{\text {th }}$ percentile (upper line) and the 25th percentile (lower line), with the horizontal midline indicating the median. The whiskers show the 90 th and 1oth percentiles. Dots indicate outlier points. 
Table 1: Number of whole blood units included in each processing methods and description of production specifications

\begin{tabular}{lll} 
Method $\mathbf{N}^{\circ}$ & $\mathbf{n}$ & $\begin{array}{l}\text { Production specifications } \\
\text { I }\end{array}$ \\
II & 145 & $\begin{array}{l}\text { Settling duration of } 36-48 \text { h plus complete removal of supernatant (until the first RBCs come into } \\
\text { the outlet tubing) } \\
\text { Settling duration of } 48-72 \text { h plus complete removal of supernatant (until the first RBCs come into } \\
\text { the outlet tubing) }\end{array}$ \\
III & 141 & $\begin{array}{l}\text { Settling duration of } 72-96 \text { h plus complete removal of supernatant (until the first RBCs come into } \\
\text { the outlet tubing) }\end{array}$ \\
IV & 139 & $\begin{array}{l}\text { Centrifugation at } 2490 \mathrm{~g} \text { for } 20 \text { minutes. A supernatant of about } 1 \text { cm high is conserved during the } \\
\text { plasma extracting }\end{array}$ \\
\hline
\end{tabular}

Abbreviations: RBC Red blood cells, $\mathrm{h}=$ Hour, g acceleration unit

Table 2: Sex ratio, age of blood donors and volume and hematological characteristics of whole blood units from group I to IV (mean $\pm \mathrm{SD}$; [range])

\begin{tabular}{lllllll} 
Group & $\begin{array}{l}\text { Sex } \\
(\mathbf{M} / \mathbf{F})\end{array}$ & Age (years) & WB_vol $(\mathrm{mL})$ & WB_Hb (g/ dL) & WB_Hct (\%) \\
& & & & & \\
I & $128 / 17$ & $23.03 \pm 3.95 ;[18-43]$ & $439.61 \pm 24.92 ;[400-496]$ & $13.23 \pm 1.01 ;[10.90-15.20]$ & $39.69 \pm 3.04 ;[32.70-45.60]$ \\
II & $107 / 34$ & $22.28 \pm 3.58 ;[18-42]$ & $441.17 \pm 25.47 ;[400-499]$ & $12.95 \pm 1.02 ;[11.00-14.90]$ & $38.84 \pm 3.06 ;[33.00-44.70]$ \\
III & $93 / 48$ & $22.94 \pm 5.95 ;[18-54]$ & $440.47 \pm 25.83 ;[400-497]$ & $13.04 \pm 1.02 ;[10.70-14.90]$ & $39.13 \pm 3.13 ;[32.10-46.80]$ \\
& & & & & \\
VI & $123 / 16$ & $25.58 \pm 7.65 ;[19-55]$ & $441.51 \pm 24.98 ;[400-500]$ & $13.76 \pm 1.07 ;[10.98-16.70]$ & $41.28 \pm 3.21 ;[32.95-50.12]$ \\
p-value & - & 0.33 & 0.87 & 0.05 & 0.05 \\
\hline
\end{tabular}

Abbreviations: M Male, F Female, WB_vol whole blood volume, WB_Hb whole blood hemoglobin level, WB_Hct whole blood hematocrit

Table 3: Proportion of red cell concentrates units meeting minimum requirements of regulatory

\begin{tabular}{|c|c|c|c|c|c|c|}
\hline \multirow{2}{*}{ Method } & \multicolumn{2}{|c|}{ Hematocrit } & \multicolumn{2}{|c|}{ Volume } & \multicolumn{2}{|c|}{ Hemoglobin content } \\
\hline & $\mathbf{n}$ & $\%$ & $\mathbf{n}$ & $\%$ & $\mathbf{n}$ & $\%$ \\
\hline I & 3 & 2.07 & 139 & 95.86 & 145 & 100 \\
\hline II & 20 & 14.18 & 141 & 100 & 141 & 100 \\
\hline III & 39 & 27.66 & 141 & 100 & 141 & 100 \\
\hline IV & 139 & 100 & 139 & 100 & 139 & 100 \\
\hline
\end{tabular}

Table 4: Comparison of the efficacy of the four methods and the characteristics of the RCCs units processed using a Tukey's HSD test

\begin{tabular}{|c|c|c|c|c|c|}
\hline Parameters & Methods & \multicolumn{2}{|c|}{ Group means } & Mean difference & HSD-test \\
\hline \multirow{6}{*}{ 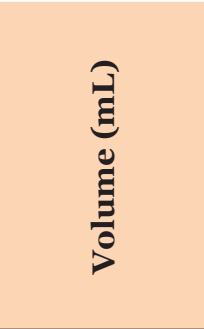 } & I vs II & 372.88 & 357.91 & 14.97 & $8.64^{*}$ \\
\hline & I vs III & 372.88 & 350.30 & 22.58 & $13.03^{*}$ \\
\hline & I vs IV & 372.88 & 332.26 & 40.62 & $23.43^{*}$ \\
\hline & II vs III & 357.91 & 350.30 & 7.61 & $4.39^{*}$ \\
\hline & II vs IV & 357.91 & 332.26 & 25.65 & $14.79^{*}$ \\
\hline & III vs IV & 350.30 & 332.26 & 18.04 & $10.40^{*}$ \\
\hline
\end{tabular}


Table 4: (Continued)

\begin{tabular}{|c|c|c|c|c|c|}
\hline \multirow{6}{*}{ 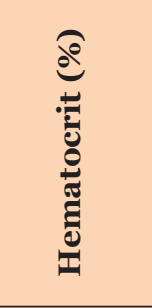 } & I vs II & 45.42 & 47.41 & 1.99 & $8.27^{*}$ \\
\hline & I vs III & $45 \cdot 42$ & 48.24 & 2.82 & $11.68^{*}$ \\
\hline & I vs IV & 45.42 & 62.28 & 16.86 & $69.99^{*}$ \\
\hline & II vs III & 47.41 & 48.24 & 0.83 & 3.41 \\
\hline & II vs IV & 47.41 & 62.28 & 14.87 & $61.72^{*}$ \\
\hline & III vs IV & 48.24 & 62.28 & 14.04 & $58.31^{*}$ \\
\hline \multirow{6}{*}{ 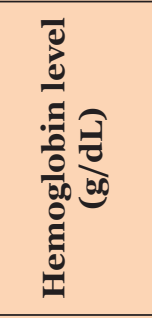 } & I vs II & 15.43 & 15.84 & 0.41 & $4.43^{*}$ \\
\hline & I vs III & 15.43 & 16.17 & 0.74 & $8.06^{*}$ \\
\hline & I vs IV & 15.43 & 19.25 & 3.82 & $41.74^{*}$ \\
\hline & II vs III & 15.84 & 16.17 & 0.33 & 3.63 \\
\hline & II vs IV & 15.84 & 19.25 & 3.41 & $37 \cdot 31^{*}$ \\
\hline & III vs IV & 16.17 & 19.25 & 3.08 & $33.68^{*}$ \\
\hline \multirow{6}{*}{ 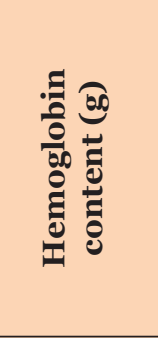 } & I vs II & 57.57 & 56.68 & 0.89 & 2.05 \\
\hline & I vs III & 57.57 & 56.66 & 0.91 & 2.11 \\
\hline & I vs IV & $57 \cdot 57$ & 63.91 & 6.34 & $14.56^{*}$ \\
\hline & II vs III & 56.68 & 56.66 & 0.02 & 0.06 \\
\hline & II vs IV & 56.68 & 63.91 & 7.23 & $16.61^{*}$ \\
\hline & III vs IV & 56.66 & 63.91 & 7.25 & $16.66^{*}$ \\
\hline \multirow{6}{*}{ 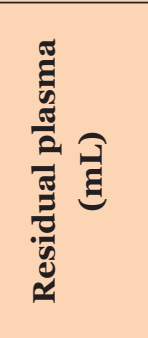 } & I vs II & 103.42 & 88.22 & 15.20 & $13.43^{*}$ \\
\hline & I vs III & 103.42 & 81.23 & 22.19 & $19.60^{*}$ \\
\hline & I vs IV & 103.42 & 25.18 & 78.24 & $69.15^{*}$ \\
\hline & II vs III & 88.22 & 81.23 & 6.99 & $6.18^{*}$ \\
\hline & II vs IV & 88.22 & 25.18 & 63.04 & $55.72^{*}$ \\
\hline & III vs IV & 81.23 & 25.18 & 56.05 & $49.54^{*}$ \\
\hline \multirow{6}{*}{ 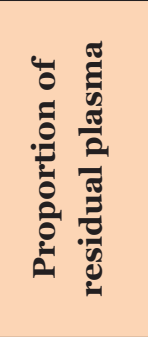 } & I vs II & 0.39 & 0.32 & 0.06 & $19.03^{*}$ \\
\hline & I vs III & 0.39 & 0.30 & 0.09 & $26.13^{*}$ \\
\hline & I vs IV & 0.39 & 0.09 & 0.30 & $87.16^{*}$ \\
\hline & II vs III & 0.32 & 0.30 & 0.03 & $7.10^{*}$ \\
\hline & II vs IV & 0.32 & 0.09 & 0.24 & $68.13^{*}$ \\
\hline & III vs IV & 0.30 & 0.09 & 0.21 & $61.04^{*}$ \\
\hline \multirow{6}{*}{ 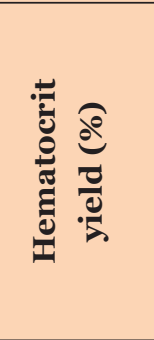 } & I vs II & 5.68 & 8.56 & 2.88 & $15.01^{*}$ \\
\hline & I vs III & 5.68 & 9.13 & 3.45 & $17.99^{*}$ \\
\hline & I vs IV & 5.68 & 21.01 & $15 \cdot 33$ & $79.89^{*}$ \\
\hline & II vs III & 8.56 & 9.13 & 0.57 & 2.98 \\
\hline & II vs IV & 8.56 & 21.01 & 12.45 & $64.88^{*}$ \\
\hline & III vs IV & 9.13 & 21.01 & 11.88 & $61.90^{*}$ \\
\hline \multirow{6}{*}{ 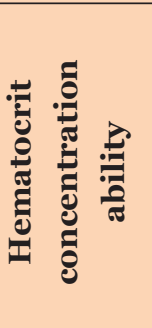 } & I vs II & 1.14 & 1.22 & 0.08 & $12.69^{*}$ \\
\hline & I vs III & 1.14 & 1.24 & 0.1 & $14.91^{*}$ \\
\hline & I vs IV & 1.14 & 1.51 & 0.37 & $60.81^{*}$ \\
\hline & II vs III & 1.22 & 1.24 & 0.02 & 2.22 \\
\hline & II vs IV & 1.22 & 1.51 & 0.29 & $48.12^{*}$ \\
\hline & III vs IV & 1.24 & 1.51 & 0.27 & $45 \cdot 90^{*}$ \\
\hline
\end{tabular}

${ }^{*} \mathrm{p}<0.05$; Studentized range critical value $(0.05,4,562)=3.644264$ 
the minimum required (at least 50\%), although this represented an increase in hematocrit level of 5.73-9.18\% compared to WB. The volume and hemoglobin content of all RCCs units was complying with the minimum requirements [17].

The main limitation of this study is related to the inability to fully standardize the technique of bags storage in the monitored temperature refrigerator. Indeed, the WB bags were ranged vertically one against the other (6-7 bags) in the refrigerator baskets for the settling duration. The sedimentation depending on the gravity and resistance forces (Archimedes thrust and friction force) [2], without any additional applied centrifugal force, the bag verticality level could influence sedimentation rate. Ideally, blood bags should be suspended to hooks by the top. The second limitation concerns the baseline differences (mainly pre-donation hemoglobin) between WB units included in processing with settling methods and centrifugation. These differences that are related to the donors' populations in the two RBTCs did not allow comparison of hemoglobin level, hemoglobin content and volume of RCCs processed by either of the two methods. However, these differences should not affect their comparability with regard to the other parameters. In addition, WB units included in the three settling methods had similar baseline characteristics, allowing comparability of RCCs obtained from them. Finally, our study has a limited global generalizability. The results presented are about only one center and a single country (RBTC of Koudougou in Burkina Faso) experience according to local context. So, the national regulatory requirements and standards would determine blood collection and transfusion practices globally.

The quality of the blood products processed is clearly influenced by blood collection, processing and storage conditions $[19,21]$. Consequently, these processes are regulated to maximize the safety and efficacy of blood products. In our context, the quality, efficacy and safety of blood products and blood transfusion are regulated by two ministerial orders. The first order describes the best practices in blood transfusion and the second one, the characteristics and standards of blood products $[16,17]$. If the intended goal is to prepare only RCCs, the WB units with a volume between $400-500 \mathrm{~mL}$ (anticoagulant taken into account) must be kept in refrigerated temperature $\left(2-6^{\circ} \mathrm{C}\right)$ and processed within 96 hours after collection. Those with a volume between $280-399 \mathrm{~mL}$ have to be processed within 24 hours. Units with a volume less than 280 must be discarded [17]. In our study, centrifugation and settling procedures have complied with these requirements. Both RCCs obtained by centrifugation and settling methods were processed respectively within 48 and 96 hours after collection. The removal of anticoagulant surplus within the 96 hours reduces RBCs' hemolysis [22-24].

The use of the WB settling method by simple gravity to obtain RCCs for blood transfusion is not novel. Several guides for clinical use of blood in countries with scarce resources describe how to prepare RCCs in order to reduce the risks of plasma-related adverse reactions [25]. According to these guidelines, WB settling is a practice to be implemented at the bedside. The bag is suspended to a bracket at bedside, top downward. Thus, according to the principle of gravity, the RBCs will sediment after a given duration and could be administered. Transfusion should be stopped before the administration of plasma. But the correct monitoring of blood transfusions is challenging due to shortage of staff in health care services. In addition, in our context where, the ambient temperature often reaches over $40^{\circ} \mathrm{C}$ in the shade, $\mathrm{WB}$ settling at bedside could favor bacterial multiplication and RBCs' hemolysis. The duration of the procedure (at least 6 hours) could also be harmful to patients who need transfusion urgently.

We implemented the method of settling WB in advance in order to solve the problems of exposition of blood to hot temperatures and their timely availability. In addition, the RCCs that were produced can be divided into pediatric units to meet the specific needs of several children in pediatric ward and avoid blood wastage. But this choice requires from our blood transfusion service, some effective strategies for blood collection to have sufficient stocks permitting such long processing durations. Fixed and mobile blood collections have been multiplied and rigorously planned to prevent the settling process from constituting an additional barrier to the continued availability of blood products. However, this is not definitively acquired. The required resources are not always available at due time, even if many efforts are made to limit it. Besides that, blood products are most often ordered in emergency situations.

The WB settling methods resulted in RCCs units with a more important volume of residual plasma and a lower hematocrit level. Indeed, the residual plasma volumes in RCCs units obtained with settling methods were 3 to 4 times higher compared to RCCs processed by centrifugation. Their hematocrit concentration abilities were also 20 to $25 \%$ lower. In many studies assessing quality of RCCs processed by centrifugation / aphaeresis methods or gravity filtration system, the hematocrit average ranged from $59.5-64.8 \%[10,21]$ and the average volume of residual plasma was around $25-30 \mathrm{~mL}$ [21]. The gravity filtration systems have hematocrit concentration ability around 2.05 according to some studies [9]. In our study, the RCCs processed by centrifugation (method IV) had similar characteristics. But, the centrifugation method in our context had an average hematocrit concentration ability of 1.51 . The settling methods I, II and III gave RCCs with hematocrit and residual plasma volume averages that ranged from 45 to $48 \%$ and 103 to $81 \mathrm{~mL}$. Their hematocrit concentration abilities were respectively 1.14, 1.22 and 1.24. The Tukey's HSD-test has shown non-significant difference between the methods II and III with respect to some of the parameters assessing the efficacy of the method (as the hematocrit yield and the hematocrit concentration ability) and characteristics of RCCs processed (hematocrit and hemoglobin level), 
suggesting that there is no more benefice of settling whole blood over a duration superior to 72 hours. This finding is interesting as the time for making available blood products with settling method will be about 3 days after collection. This remains superior to the mean time of 48 hours necessary (laboratory testing taken into account) at the RBTC of Ouagadougou with centrifugation method (quality control data).

Before the addition of preservative solution, RCCs prepared after settling duration of $36-48 \mathrm{~h}$ had an average hematocrit of $59.27 \%$, representing a hematocrit concentration ability of 1.30 (data not presented). The addition of preservative solution dilutes the RBCs and the hematocrit decreases for a range of 15 to $11 \%$.

Addition of preservative solution improves the quality of RCCs, extends their conservation duration and allows maximum extraction of plasma from WB for the fractionation industry $[19,22-24,26]$. The third objective is not applicable with the WB settling method. Concerning the extension of conservation duration of RCCs, the question is whether we really need to keep RCCs so long in our context, given the inadequacy of blood collection and the high frequency of demand in RCCs? It might be therefore interesting to assess the maximum storage duration of RCCs before their issue for transfusion to determine whether adding preservative solution is essential for this purpose. It might also be necessary to investigate the storage lesions and adverse reactions achieved with these types of RCCs containing a high residual plasma level (81 to $103 \mathrm{~mL}$ versus 25$30 \mathrm{~mL}$ in RCCs prepared by centrifugation and gravity filtration methods).

Normally, a range of blood components including RCCs, PCs, FFP, can be obtained from the processing of single WB donations. But the WB settling method by simple gravity does not allow the preparation of PCs and therapeutic plasma. Indeed, the principle of blood components processing is based on the capacity of blood cells to sediment [8]. With centrifugation and aphaeresis methods, an external centrifugal force is applied to blood cells and favors cells sedimentation, even the smallest like platelets. In WB settling method, the gravity force is not sufficient to allow their good-sedimentation. The collected plasma cannot be used in therapeutic because of processing duration. The regulations stipulate that when PCs have to be prepared, the WB must be stored at room temperature and process within 24 hours after collection or within 18 hours if FFP is planned to be produced [17]. When WB is refrigerated, platelet cells are inactivated and the clotting factors are destroyed after 24 hours [21]. The different settling times evaluated in our study did not meet these requirements.

For low-incomes countries, a main question could be raised. Is it necessary to invest in complex facilities and equipment for all blood transfusion services in the country in order to produce these different blood products? The aim of modern transfusion therapy being to provide appropriate replacement therapy with blood components $[1,2]$, the product of choice in African countries is mainly the RCCs given the epidemiological profile characterized by the high prevalence of malarial anemia, obstetric hemorrhages and malnutrition [2729]. In some countries, the use of RCCs accounted for up to $85 \%$ and FFP less than $10 \%$ [30, 31]. These countries being faced enormous economic constraints, the WB settling method could permit to blood services to produce blood products adapted to their clinical needs while being better than WB. This also will result in reduction of production costs, contributing thus to blood services sustainability [28, 29, 32, 33]. Adoption of this strategy implies necessary reorganization of blood transfusion policy and implementation of pro-active blood collection strategies. Facilities and infrastructures for centrifugation or aphaeresis could be developed in some strategic blood services, taking into account the road network. The FFP and PCs produced in these well-equipped blood services could thereafter be dispatched in the other blood services or hospitals. In our context, the needs in FFP and PCs for patients in areas of RBTC of Koudougou are covered by the RBTC of Ouagadougou, located 1.5 hours away from Koudougou.

\section{CONCLUSION}

By this study, we can define some preliminary characteristics and standards for the red cell concentrates (RCCs) processed by settling methods. They had intermediate hematocrit and residual plasma and we observed significant differences between these RCCs and those got by centrifugation. These differences will certainly have a significant clinical impact depending on whether the RCCs from one or the other method are used. In the context of inadequate blood collection in developing countries, the blood services can implement the whole blood settling method with a maximum settling duration of 72 hours (method III), while revising their blood collection strategies and services organization. Our conviction is that transfusion from WB settling methods was preferable to simple WB. Indeed, with the RCCs issued from settling method, the needed volume to be administered could be reduced and post transfusion hemoglobin increase could be significant compared to WB. But all these hypotheses have to be verified by further studies that would establish the validity of this process. They will focus first, on the way to control and standardize the process in order to improve its consistency and results. After that, they must investigate the transfusion rules and patient outcome such as required volume to be administered, efficacy (post transfusion hemoglobin increase) and safety (frequency and types of adverse reactions). A better control of these critical issues may give Sub-Saharan African countries the possibility to improve their blood transfusion practices while ensuring sustainability of their system. 


\section{Acknowledgements}

We acknowledge both staff of RBTC of Koudougou and Ouagadougou for having facilitated this study.

\section{Author Contributions}

Salam Sawadogo - Substantial contributions to conception and design, Acquisition of data, Analysis and interpretation of data, Drafting the article, Revising it critically for important intellectual content, Final approval of the version to be published

Kompingnin Nébié - Substantial contributions to conception and design, Revising it critically for important intellectual content, Final approval of the version to be published

Eléonore Kafando - Substantial contributions to conception and design, Revising it critically for important intellectual content, Final approval of the version to be published

Tieba Millogo - Substantial contributions to conception and design, Analysis and interpretation of data, Revising it critically for important intellectual content, Final approval of the version to be published

Siaka Ouattara - Substantial contributions to conception and design, Analysis and interpretation of data, Revising it critically for important intellectual content, Final approval of the version to be published

Honorine Dahourou - Substantial contributions to conception and design, Analysis and interpretation of data, Revising it critically for important intellectual content, Final approval of the version to be published Georges Ouédraogo - Acquisition of data, Revising it critically for important intellectual content, Final approval of the version to be published

Sibiri Nana - Acquisition of data, Revising it critically for important intellectual content, Final approval of the version to be published

Véronique Deneys - Substantial contributions to conception and design, Analysis and interpretation of data, Revising it critically for important intellectual content, Final approval of the version to be published

\section{Guarantor}

The corresponding author is the guarantor of submission.

\section{Conflict of Interest}

Authors declare no conflict of interest.

\section{Copyright}

(C) 2016 Salam Sawadogo et al. This article is distributed under the terms of Creative Commons Attribution License which permits unrestricted use, distribution and reproduction in any medium provided the original author(s) and original publisher are properly credited. Please see the copyright policy on the journal website for more information.

\section{REFERENCES}

1. Devine DV, Serrano K. Preparation of blood products for transfusion: is there a best method? Biologicals 2012 May;40(3):187-90.

2. Delobel J, Rubin O, Prudent M, Crettaz D, Tissot JD, Lion N. Biomarker analysis of stored blood products: emphasis on pre-analytical issues. Int J Mol Sci 2010 Nov 17;11(11):4601-17.

3. World Health Organization. Pocket Book of Hospital Care for Children: Guidelines for the Management of Common Illnesses with Limited Resources. Geneva: WHO Press; 2005. [Available at: www.who.int/maternal_child_adolescent/ documents/9241546700/en/]

4. Brabin BJ, Premji Z, Verhoeff F. An analysis of anemia and child mortality. J Nutr 2001 Feb;131(2S2):636S-645S; discussion $646 \mathrm{~S}-8 \mathrm{~S}$.

5. Lackritz EM, Hightower AW, Zucker JR, et al. Longitudinal evaluation of severely anemic children in Kenya: the effect of transfusion on mortality and hematologic recovery. AIDS 1997 Oct;11(12):148794.

6. Kiguli S, Maitland K, George EC, et al. Anaemia and blood transfusion in African children presenting to hospital with severe febrile illness. BMC Med 2015 Feb 2;13:21.

7. European Directorate for the Quality of Medicines \& Healthcare. Guide to the Preparation, Use and Quality Assurance of Blood Components: Recommendation Number R (95) 15. 18ed. Strasbourg: EDQM of the Council of Europe; 2015. p. 85-95.

8. Greening DW, Glenister KM, Sparrow RL, Simpson RJ. International blood collection and storage: clinical use of blood products. J Proteomics 2010 Jan 3;73(3):386-95.

9. Brune T, Hannemann-Pohl K, Nißle K, Ecker N, Garritsen H. Quality, stability, and safety data of packed red cells and plasma processed by gravity separation using a new fully integrated hollow-fibre filter device. Adv Hematol 2009;2009:175234.

10. Sekiguchi S, Takahashi TA, Yamamoto S, et al. A new type of blood component collector: plasma separation using gravity without any electrical devices. Vox Sang 1990;58(3):182-7.

11. Hornsey VS, McColl K, Drummond O, Prowse CV. Separation of whole blood into plasma and red cells by using a hollow-fibre filtration system. Vox Sang 2005 Aug;89(2):81-5.

12. Allain JP, Owusu-Ofori S, Bates I. Blood Transfusion in Sub-Saharan Africa. Transfus Altern Transfus Med 2004;6(1):16-23.

13. Ibrahim NU, Garba N, Tilde IM. Acute Blood Transfusion Reactions in Pregnancy, an Observational Study from North Eastern Nigeria. J Blood Disord Transfus 2013;4:145.

14. Mafirakureva N, Khoza S, Mvere DA, Chitiyo ME, Postma MJ, Van Hulst M. Incidence and pattern of 12 years of reported transfusion adverse events in Zimbabwe: a retrospective analysis. Blood Transfus 2014 Jul;12(3):362-7.

15. Nébié K, Ouattara S, Sanou M, et al. Poor procedures and quality control among nonaffiliated blood centers in Burkina Faso: an argument for expanding the reach 
of the national blood transfusion center. Transfusion 2011 Jul;51(7 Pt 2):1613-8.

16. Ministry of Health, Burkina Faso. Ministerial Order No. 2008/271/MS of 18 July 2007 laying down national guidelines of Good transfusion practices in Burkina Faso (in French).

17. Ministry of Health, Burkina Faso. Ministerial Order No. 2008/272/MS of 18 July 2007 laying down standards and specifications of labile blood products in Burkina Faso (in French).

18. D’Amici GM, Mirasole C, D’Alessandro A, Yoshida T, Dumont LJ, Zolla L. Red blood cell storage in SAGM and AS3: a comparison through the membrane two-dimensional electrophoresis proteome. Blood Transfus 2012 May;10 Suppl 2:s46-54.

19. Hess JR. An update on solutions for red cell storage. Vox Sang 2006 Jul;91(1):13-9.

20. Winters JL, Gottschall JL. eds. Therapeutic Aphaeresis: a Physician's Handbook. 3ed. American Association of Blood Banks \& American Society for Apheresis. 2011.

21. Hansen AL, Kurach JD, Turner TR, et al. The effect of processing method on the in vitro characteristics of red blood cell products. Vox Sang 2015 May;108(4):3508.

22. Veale MF, Healey G, Sparrow RL. Effect of additive solutions on red blood cell (RBC) membrane properties of stored RBCs prepared from whole blood held for 24 hours at room temperature. Transfusion 2011 Jan;51 Suppl 1:25S-33S.

23. D'Alessandro A, Nemkov T, Kelher M, et al. Routine storage of red blood cell (RBC) units in additive solution-3: a comprehensive investigation of the RBC metabolome. Transfusion 2015 Jun;55(6):1155-68.
24. Flegel WA, Natanson C, Klein HG. Does prolonged storage of red blood cells cause harm? Br J Haematol 2014 Apr;165(1):3-16.

25. Doctors without Borders. Practical Guide to the Use of Doctors, Nurses and Laboratory Technicians (in French). MSF, 2010.

26. Sparrow RL. Time to revisit red blood cell additive solutions and storage conditions: a role for "omics" analyses. Blood Transfus 2012 May;10 Suppl 2:s7-11.

27. Lackritz EM, Campbell CC, Ruebush TK 2nd, et al. Effect of blood transfusion on survival among children in a Kenyan hospital. Lancet 1992 Aug 29;340(8818):524-8.

28. Field SP, Allain JP. Transfusion in sub-Saharan Africa: does a Western model fit? J Clin Pathol 2007 Oct;60(10):1073-5.

29. Ala F, Allain JP, Bates I, et al. External financial aid to blood transfusion services in sub-Saharan Africa: a need for reflection PLoS Med 2012;9(9):e1001309.

30. Mafirakureva N, Khoza S, Hassall O, et al. Profiles of blood and blood component transfusion recipients in Zimbabwe. Blood Transfus 2015 Oct;13(4):600-9.

31. Natukunda B, Schonewille H, Smit Sibinga CT. Assessment of the clinical transfusion practice at a regional referral hospital in Uganda. Transfus Med 2010 Jun;20(3):134-9.

32. Diane MK, Dembele B, Konate S. Blood collection to cover national needs in sub-Saharan Africa: the reality of the Ivory Coast. Blood Transfus 2014 Oct;12(4):624-5.

33. Hensher M, Jefferys E. Financing blood transfusion services in sub-Saharan Africa: a role for user fees? Health Policy Plan 2000 Sep;15(3):287-95.
Access full text article on other devices

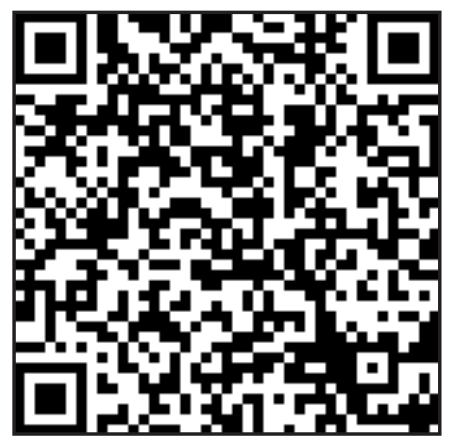

Access PDF of article on other devices

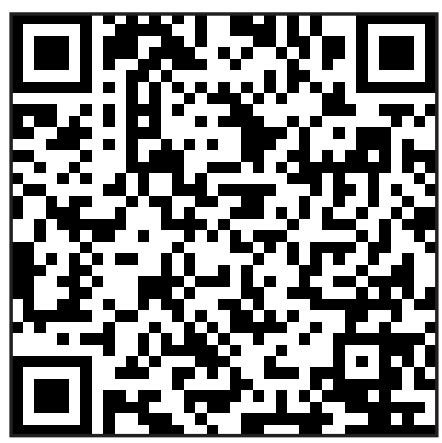

